\title{
Predictors of nausea and vomiting risk factors and its relation to anesthesia in a teaching hospital
}

\author{
Subhi Al-Ghanem¹, Muayyad Ahmad ${ }^{2 *}$, Ibraheem Qudaisat ${ }^{1}$, Walid Samarah ${ }^{1}$, Khaled Al-Zaben ${ }^{1}$, Sami Abu Halaweh ${ }^{1}$, Omar Ababneh ${ }^{1}$, \\ Fathi Abu Masaid ${ }^{1}$, Fadi Qutishat ${ }^{1}$, Zaineh Altabari ${ }^{1}$, Ahmad Obeidat ${ }^{1}$, Qusai Alamoudi ${ }^{1}$ and Marwan Zoubi ${ }^{1}$ \\ ${ }^{1}$ Department of Anesthesia, Faculty of Medicine, University of Jordan, 11942, Jordan \\ ${ }^{2}$ Department of Clinical Nursing, School of Nursing, University of Jordan, 11942, Jordan
}

\begin{abstract}
Purpose: This study was conducted to estimate the incidence of postoperative nausea and vomiting (PONV) and to explore the risk factors that increase the development of PONV.

Methods: A prospective study design was used to observe nausea and vomiting 24 hours postoperatively, over a 6-month period. The study sample was composed of 2,398 patients aged between 1 and 87 years. Chi-square and logistic regression were used to identify the risk factors for predicting PONV.

Results: A total of 747 patients (31.2\%) suffered from nausea, and 268 patients (11.2\%), suffered from vomiting. Female patients and who received anesthesia more than 60 minutes, nauseated more in the recovery room and 24 hours after surgery. Female patients vomited more in the recovery and later during 24 hours; and those who received anesthesia more than 60 minutes, and who received postoperative opioids have vomited more during 24 hours after surgery. Female gender, postoperative opioids and anesthesia duration more than 60 minutes are predictive risk factors for nausea; while female gender and duration of anesthesia more than 60 minutes are predictive risk factors for vomiting.
\end{abstract}

Conclusions: Female gender, use of postoperative opioids and duration of anesthesia are the most important predictive risk factors for PONV. Nonsmoking status, previous history of PONV and type of anesthesia were not found as risk factors for PONV.

\section{Introduction}

Nausea and vomiting are common complications after anesthesia and surgery. The incidence of postoperative nausea and vomiting (PONV) ranges from 20-30\%, [1], but this incidence may increase up to $80 \%$ in patients with more risk factors and in certain types of surgery [2]. Although most of PONV episodes are mild and transient, possible serious complications may occur $[3,4]$.

Despite the tremendous improvement in anesthesia and surgical techniques and practices, there is still no significant reduction in PONV rate without giving prophylaxis or treatment for this problem $[5,6]$. In Jordan, there is a paucity of literature on the incidence and risk factors of PONV. Only one study was found, which examined pain score in the correlation with PONV [7]. They found that being female, young age (19-35), and or with body weight 61-80 $\mathrm{kg}$ were predictive factors for the increased risk for nausea and vomiting. Therefore, there was a need to conduct this study to get a representative numerical estimate of PONV rate and to analyze predictive risk factors associated with it at our institute under different surgical procedures.

\section{Methods}

\section{Design}

This study has applied the prospective design to observe the incidence of PONV among the study sample. The study has covered 13 types of surgical procedures in 14 operating theatres over six month's period in the year 2016.

\section{Sample and setting}

The total number of the study participants was 2,398 patients. The study was conducted in a major teaching hospital in Jordan.

\section{Eligibility criteria}

In-patients of both genders, with American Society of Anesthesiologists (ASA) 1-3 physical status classifications scheduled to undergo different types of surgery under general or local anesthesia were included. Day-case surgery patients and who were given prophylactic antiemetics were not included in the study. Patients were not pre-medicated before anesthesia and surgery. The anesthetic staff uses their usual practice in the management of patients.

\section{Procedure}

The intervals of observations post operatively for nausea and vomiting were in the post anesthesia care unit (PACU) and 24 hours later in surgical wards. The anesthesia residents in the operating theatres completed the items on patient's characteristics, anesthesia given and surgical procedure and wrote medications for post-operative pain.

${ }^{\star}$ Correspondence to: Muayyad Ahmad, Department of Clinical Nursing, School of Nursing, University of Jordan, 11942, Jordan, Tel: 962799313745; Fax: 96265300244; E-mail: mma4@ju.edu.jo/mma4jo@yahoo.com

Key words: anesthesia, nausea, vomiting, risk factors, postoperative

Received: December 21, 2018; Accepted: January 14, 2019; Published: January 17,2019 
Nurses in PACU recorded nausea and vomiting events that occurred to patients, retching episodes were considered vomiting and were also recorded by PACU nurses. Twenty-four hours later in the surgical ward, the patients were interviewed for the occurrence of nausea and vomiting or retching by the on-call anesthesia residents. The authors reviewed the questionnaire to ensure completeness of data.

\section{Measures}

The patient questionnaire contains items related to patient characteristics; details of anesthetic management and surgery performed, and items on the postoperative outcome related to PONV. The severities of both nausea and vomiting were assessed by counting the number of events per patient that occurred over 24 hours post operatively and graded into 4 levels: $0=$ none; $1=$ mild; $2=$ moderate; 3 or more episode $=$ severe.

\section{Ethical issues}

Ethical approval for this study was obtained by the institution review board of the hospital where the study was conducted. The confidentiality and anonymity for all patients and the obtained data are protected.

\section{Statistical analyses}

Data were analyzed using Statistical Package for Social Sciences (SPSS) [8].The following factors were analyzed by Chi-square test to see their effect on the incidence of PONV, male and female gender, age of the patients, smoking and nonsmoking status, history of PONV or motion sickness or migraine, the use of postoperative opioids, type of anesthesia given, local or general, the duration of anesthesia administration and the type of surgery performed. Logistic regression was used to predict the risk factors for the development of PONV.

\section{Results}

Questionnaires and interviews were completed for 2,398 patients of whom 1,497 were females (62.4\%). The age distribution of patients was between 1-87 years, with a mean of 40.68 and standard deviation of 17.68. The number of patients who were regular smokers was 648 of whom 299 were females and 349 were males. $20 \%$ of female patients in the study were smokers, while $38.7 \%$ of the male patients were smokers. Patients with history of previous PONV or motion sickness were only 71 patients. General anesthesia was used in 2184 patients $(91.08 \%)$, while local anesthesia was used in 214 (8.92\%) patients.

Intravenous induction agents used were propofol, and midazolam, inhalational agents used were sevoflurane or isoflurane in oxygen mixed with air, nitrous oxide was not used in this study, the muscle relaxants used were cisatracurium and rocuronium, laryngeal mask airway or endotracheal intubation were used for ventilation. Drugs used in spinal or epidural block were bupivacaine local anesthetic and fentanyl. Postoperative pain was treated by intermittent intravenous or intramuscular injections of pethidine or morphine in 497 patients. Nonsteroidal anti-inflammatory drugs were used in the rest of patients according to their need. The duration of anesthesia was between 20 to 720 minutes with mean of 82.39 and standard deviation of 53.47. Patients distribution according to type of surgical procedures are shown in Table 1.

747 patients (31.2\%) and 268 patients (11.2\%) suffered from nausea and vomiting respectively during the study period.

Thirty six percent of nausea episodes and $32 \%$ of vomiting episodes occurred in PACU. Seven and a half percent and $1.6 \%$ of patients suffered from severe nausea and vomiting (Table 2). There were no reported complications related to PONV during the study. Ninety four percent of vomiting episodes preceded by nausea.

PONV outcome related to patients gender indicate that female patients nauseated 1.9 time more than male patients in the recovery room and 1.8 times within 24 hours after surgery. Patients who were less than 40 years nauseated more in the recovery room, while this was not statistically significant among age groups within 24 hours post operatively. Nonsmoking status patients, those with history of PONV and type of anesthesia local or general did not show statistical difference in relation to nausea in the recovery room and within 24 hours post operatively. Patients received postoperative opioids nauseated more within 24 hours while patients received anesthesia $>60$ minute nauseated more in the recovery room and within 24 hours after surgery (Table 3 ).

Table 4 indicates that female patients vomited more than male patients in the recovery room and during 24 hours postoperatively. Patients who received anesthesia $>60$ minute and patients who had opioids in the postoperative period vomited also more than other patients during 24 hours postoperatively but not in the recovery room. Age of patients, smoking status, previous PONV and type of anesthesia did not show statistical difference for vomiting.

Table 1. Patient characteristics, anesthetic and surgical data $(\mathrm{N}=2,398)$

\begin{tabular}{|c|c|c|c|c|c|}
\hline Variable & Number & $\%$ & Mean & $\begin{array}{l}\text { Standard } \\
\text { Deviation }\end{array}$ & Range \\
\hline Age (years) & & & 40.68 & 17.68 & $1-87$ \\
\hline Duration of anesthesia (minutes) & & & 82.39 & 53.47 & $20-720$ \\
\hline \multicolumn{3}{|l|}{ Gender } & & & \\
\hline Female & 1497 & 62.4 & & & \\
\hline Male & 901 & 37.6 & & & \\
\hline \multicolumn{3}{|l|}{ Smoking status } & & & \\
\hline Smoker & 648 & 27 & & & \\
\hline Nonsmoker & 1750 & 73 & & & \\
\hline $\begin{array}{l}\text { History of PONV or } \\
\text { migraine or motion sickness }\end{array}$ & 71 & 3 & & & \\
\hline \multicolumn{3}{|l|}{ Type of anesthesia } & & & \\
\hline Propofol, Fentanyl, Isoflurane & 2075 & 85.5 & & & \\
\hline TIVA+,Remifentanil & 109 & 4.6 & & & \\
\hline Spinal and epidural block & 190 & 7.9 & & & \\
\hline Local infiltration with sedation & 24 & 1 & & & \\
\hline Use of postoperative opioids & 497 & 20.7 & & & \\
\hline \multicolumn{3}{|l|}{ Types of surgery } & & & \\
\hline Obstetrics and gynecology & 570 & 23.8 & & & \\
\hline General surgery & 506 & 21.1 & & & \\
\hline Ear, nose, $\&$ throat & 220 & 9.2 & & & \\
\hline Orthopedics & 252 & 10.5 & & & \\
\hline Urology & 287 & 12 & & & \\
\hline Laparoscopy & 303 & 12.6 & & & \\
\hline Others & 260 & 10.9 & & & \\
\hline
\end{tabular}

+ TIVA=Total intravenous anesthesia

Table 2. Postoperative nausea and vomiting ( $\mathrm{PONV}$ ) data $(\mathrm{N}=2,398)$

\begin{tabular}{|c|c|c|c|c|}
\hline \multirow{2}{*}{ Variable } & \multicolumn{2}{|c|}{ Nausea } & \multicolumn{2}{c|}{ Vomiting } \\
\cline { 2 - 5 } & $\mathrm{n}$ & $\%$ & $\mathrm{n}$ & $\%$ \\
\hline Incidence in the PACU & 269 & 11.2 & 87 & 3.6 \\
\hline 2 2-24 hours & 478 & 19.9 & 181 & 7.5 \\
\hline Overall incidence & 747 & 31.2 & 268 & 11.2 \\
\hline Mild & 325 & 13.6 & 166 & 6.9 \\
\hline moderate & 242 & 10.1 & 63 & 2.6 \\
\hline Severe & 180 & 7.5 & 39 & 1.6 \\
\hline
\end{tabular}

Data are presented as percentage of patients; $\sim \mathrm{PACU}=$ Post anesthesia care unit 
Table 3. Nausea occurrence in recovery room and during the 24 hours after surgery $(\mathrm{N}=2,398)$

\begin{tabular}{|c|c|c|c|c|c|}
\hline \multicolumn{6}{|c|}{ Nausea } \\
\hline Characteristics & Time & $\begin{array}{c}\text { No } \\
\text { n (\%) }\end{array}$ & $\begin{array}{c}\text { Yes } \\
\text { n (\%) }\end{array}$ & $\begin{array}{c}\text { Chi } \\
\text { Square }\end{array}$ & $\begin{array}{l}\text { Odds } \\
\text { Ratio }\end{array}$ \\
\hline \multicolumn{6}{|c|}{ Gender } \\
\hline Male & \multirow{2}{*}{ In Recovery } & $832(92.3)$ & $69(7.7)$ & \multirow{2}{*}{$18.36^{* * *}$} & \multirow{2}{*}{1.86} \\
\hline Female & & $1297(86.6)$ & $200(13.4)$ & & \\
\hline Male & \multirow{2}{*}{$0-24$ hours } & $688(76.4)$ & $213(23.6)$ & \multirow{2}{*}{$37.96^{* * *}$} & \multirow{2}{*}{1.79} \\
\hline Female & & $963(64.3)$ & $534(35.7)$ & & \\
\hline \multicolumn{6}{|c|}{ Age } \\
\hline$\leq 40$ & \multirow{2}{*}{ In Recovery } & 1062 (87.6) & $151(12.4)$ & \multirow{2}{*}{$3.73^{*}$} & \multirow{2}{*}{0.78} \\
\hline$>40$ & & $1067(90.0)$ & $118(10.0)$ & & \\
\hline$\leq 40$ & \multirow{2}{*}{$0-24$ hours } & $820(67.6)$ & $393(32.4)$ & \multirow{2}{*}{1.78} & \multirow{2}{*}{0.89} \\
\hline$>40$ & & $831(70.1)$ & 354 (29.9) & & \\
\hline \multicolumn{6}{|c|}{ Smoking } \\
\hline No & \multirow{2}{*}{ In Recovery } & 1549 (88.5) & $201(11.5)$ & \multirow{2}{*}{0.47} & \multirow{2}{*}{0.9} \\
\hline Yes & & $580(89.5)$ & $68(10.5)$ & & \\
\hline No & \multirow{2}{*}{$0-24$ hours } & $1196(68.3)$ & $554(31.7)$ & \multirow{2}{*}{0.77} & \multirow{2}{*}{0.92} \\
\hline Yes & & $455(70.2)$ & $193(29.8)$ & & \\
\hline \multicolumn{6}{|c|}{ Previous PONV } \\
\hline No & \multirow{2}{*}{ In Recovery } & 2067 (88.8) & $260(11.2)$ & \multirow{2}{*}{0.19} & \multirow{2}{*}{1.2} \\
\hline Yes & & $62(87.3)$ & $9(12.7)$ & & \\
\hline No & \multirow{2}{*}{$0-24$ hours } & $1603(68.9)$ & $724(31.1)$ & \multirow{2}{*}{0.05} & 106 \\
\hline Yes & & $48(67.6)$ & $23(32.4)$ & & 1.00 \\
\hline & & Postop Opio & & & \\
\hline No & & $1688(88.8)$ & $213(11.2)$ & & \\
\hline Yes & In Recovery & $441(88.7)$ & $56(11.3)$ & 0.01 & 1.01 \\
\hline No & 024 bour & $1362(71.6)$ & $539(28.4)$ & 234 & 182 \\
\hline Yes & $0-24$ nours & $289(58.1)$ & $208(41.9)$ & 53.41 & 1.02 \\
\hline & & Anesthesia & & & \\
\hline Local & In Recover & $193(90.2)$ & $21(9.8)$ & 047 & 118 \\
\hline General & III Kecovery & 1936 (88.6) & $248(11.4)$ & $0.4 \%$ & 1.10 \\
\hline Local & $0-24$ hours & $150(70.1)$ & 64 (29.9) & 017 & 107 \\
\hline General & $0-24$ hours & $1501(68.7)$ & $683(31.3)$ & 0.17 & 1.07 \\
\hline & & uration of anes & thesia & & \\
\hline$\leq 60$ & & $1085(90.0)$ & $120(10.0)$ & $386 \div-3$ & 120 \\
\hline$>60$ & In Recovery & $1044(87.5)$ & $149(12.5)$ & 3.86 & 1.29 \\
\hline$\leq 60$ & 024 b & $876(72.7)$ & $329(27.3)$ & & 14 \\
\hline$>60$ & $0-24$ hours & $775(65.0)$ & $418(35.0)$ & 16.72 & 1.44 \\
\hline
\end{tabular}

${ }^{*} p<.05 ;{ }^{* * *} p<.01 ;{ }^{* * * *} p<.001$

The logistic model to predict the occurrence of nausea that adequately fitted the data (Hosmer and lemeshow=3.97, 7 degrees of freedom, $\mathrm{P}=0.80)$ included seven predictor variables with Chisquare $=83.75(\mathrm{P}<0.001)$. The estimate of variance accounted for the nausea episodes are 3.7\% (Cox and Snell) and 5.1\% (Nagelkerke)

Three predictors of nausea were significant at $p<0.001$; female patients, use of postoperative opioids and duration of anesthesia more than 1hour (Table 5).

The logistic regression model to predict the occurrence of vomiting that adequately fitted the data (Hosmer and lemeshow $=5.65$, 7 degrees of freedom, $\mathrm{P}=0.69)$ included seven predictor variables with Chi-square $=29.24 \quad(\mathrm{P}<0.001)$. The estimate of variance accounted for the vomiting episodes are $1.3 \%$ (Cox and Snell) and $2.7 \%$ (Nagelkerke). Two predictors were significant at $\mathrm{P}<0.001$; female gender, use of postoperative opioids and duration of anesthesia more than 60 minute (Table 6).

Comparing the patients according to the types of surgery with the occurrence of nausea (Chi-square $=67.21, \mathrm{p}<0.001$ ) and vomiting (Chi-square $=26.73, \mathrm{P}<0.001$ ) based on the adjusted residual value (more than 1.96) for each pair of comparison, the Chi-square was considered significant. Obstetric and gynecologic, orthopedic, urologic and laparoscopic surgery were significant for the occurrence of nausea, while laparoscopic and urologic surgery were significant for the occurrence of vomiting (Table 7).

Table 4. Vomiting occurrence in recovery room and during the 24 hours after surgery $(\mathrm{N}=2,398)$

\begin{tabular}{|c|c|c|c|c|c|}
\hline \multicolumn{6}{|c|}{ Vomiting } \\
\hline Characteristics & Time & $\begin{array}{c}\text { No } \\
\text { n (\%) }\end{array}$ & $\begin{array}{c}\text { Yes } \\
\text { n (\%) }\end{array}$ & $\begin{array}{c}\text { Chi } \\
\text { Square }\end{array}$ & $\begin{array}{l}\text { Odds } \\
\text { Ratio }\end{array}$ \\
\hline \multicolumn{6}{|c|}{ Gender } \\
\hline Male & \multirow{2}{*}{ In Recovery } & $883(98.0)$ & $18(2.0)$ & \multirow{2}{*}{$10.97^{* * *}$} & \multirow{2}{*}{2.37} \\
\hline Female & & $1428(95.4)$ & $69(4.6)$ & & \\
\hline Male & \multirow{2}{*}{$0-24$ hours } & $832(92.3)$ & 69 (47.7) & \multirow{2}{*}{$17.99^{* * * *}$} & \multirow{2}{*}{1.85} \\
\hline Female & & $1298(86.7)$ & $199(13.3)$ & & \\
\hline \multicolumn{6}{|c|}{ Age (years) } \\
\hline$\leq 40$ & \multirow{2}{*}{ In Recovery } & $1162(95.8)$ & $51(4.2)$ & \multirow{2}{*}{2.33} & \multirow{2}{*}{0.71} \\
\hline$>40$ & & $1149(97.0)$ & $36(3.0)$ & & \\
\hline$\leq 40$ & \multirow{2}{*}{$0-24$ hours } & $1074(88.5)$ & $139(11.5)$ & \multirow{2}{*}{0.2} & \multirow{2}{*}{0.94} \\
\hline$>40$ & & $1056(89.1)$ & $129(10.9)$ & & \\
\hline \multicolumn{6}{|c|}{ Smoking } \\
\hline No & \multirow{2}{*}{ In Recovery } & $1679(95.9)$ & $71(4.1)$ & \multirow{2}{*}{3.41} & \multirow{2}{*}{0.6} \\
\hline Yes & & $632(97.5)$ & $16(2.5)$ & & \\
\hline No & \multirow{2}{*}{$0-24$ hours } & $1543(88.2)$ & $207(11.8)$ & \multirow{2}{*}{2.78} & \multirow{2}{*}{0.78} \\
\hline Yes & & 587 (90.6) & $61(9.4)$ & & \\
\hline \multicolumn{6}{|c|}{ Previous PONV } \\
\hline No & In Recovery & $2242(96.3)$ & $85(3.7)$ & \multirow{2}{*}{0.14} & \multirow{2}{*}{0.77} \\
\hline Yes & & $69(97.2)$ & $2(2.8)$ & & \\
\hline No & \multirow{2}{*}{$0-24$ hours } & $2067(88.8)$ & $260(11.2)$ & \multirow{2}{*}{0.01} & \multirow{2}{*}{1.01} \\
\hline Yes & & $63(88.7)$ & $8(11.3)$ & & \\
\hline & & Postoperative & Opioids & & \\
\hline No & In Recovery & $1828(96.2)$ & $73(3.8)$ & 118 & 073 \\
\hline Yes & In Recovery & $483(97.2)$ & $14(2.8)$ & 1.18 & 0.13 \\
\hline No & 024 b & $1703(89.6)$ & $198(10.4)$ & 5214 & 14 \\
\hline Yes & $0-24$ nours & 427 (85.9) & $70(14.1)$ & 5.34 & 1.41 \\
\hline & & Anesthe & & & \\
\hline Local & In Pecoyer & $206(96.3)$ & $8(3.7)$ & 001 & 097 \\
\hline General & in kecovery & 2105 (96.4) & 79 (3.6) & 0.01 & 0.91 \\
\hline Local & $0-24$ bours & $185(86.4)$ & $29(13.6)$ & 134 & 0.78 \\
\hline General & $0-24410 \mathrm{drs}$ & $1945(89.1)$ & $239(10.9)$ & & \\
\hline & & Duration of an & esthesia & & \\
\hline$\leq 60$ & In D & $1167(96.8)$ & $38(3.2)$ & 156 & 132 \\
\hline$>60$ & 11 кесоvену & $1144(95.9)$ & $49(4.1)$ & 1.50 & 1.52 \\
\hline$\leq 60$ & 24 baurs & $1091(90.5)$ & $114(9.5)$ & $718^{* * *}$ & 142 \\
\hline$>60$ & & $1039(87.1)$ & $154(12.9)$ & 7.18 & 1.42 \\
\hline
\end{tabular}

Table 5. Logistic regression to predict nausea $(\mathrm{N}=2,398)$

\begin{tabular}{|c|c|c|c|c|}
\hline Variables & B & SE & Wald & Odds ratio \\
\hline Gender & .61 & .10 & $38.28^{*}$ & 1.84 \\
\hline Age & -.01 & .01 & 2.82 & .99 \\
\hline Smoking & .01 & .11 & .02 & 1.01 \\
\hline Previous PONV & -.04 & .26 & .02 & .96 \\
\hline Postoperative Opioids & .58 & .11 & $29.16^{*}$ & 1.78 \\
\hline Anesthesia type & .07 & .16 & .20 & 1.08 \\
\hline Anesthesia duration & .35 & .09 & $14.98^{*}$ & 1.42 \\
\hline
\end{tabular}

" $p<.001$ 
Table 6. Logistic regression to predict vomiting $(\mathrm{N}=2,398)$

\begin{tabular}{|c|c|c|c|c|}
\hline Variables & B & SE & Wald & Odds ratio \\
\hline Gender & .61 & .15 & $16.28^{* * *}$ & 1.83 \\
\hline Age & -.01 & .01 & .07 & .99 \\
\hline Smoking & -.14 & .16 & .78 & .87 \\
\hline Previous PONV & -.10 & .38 & .07 & .90 \\
\hline Postoperative Opioids & .31 & .15 & $4.11^{*}$ & 1.36 \\
\hline Anesthesia type & -.22 & .22 & 1.02 & .80 \\
\hline Anesthesia duration & .33 & .13 & $6.35^{* *}$ & 1.40 \\
\hline
\end{tabular}

" $\mathrm{p}<.05 ;{ }^{* * *} \mathrm{p}<.01 ;{ }^{* * *} \mathrm{p}<.001$

Table 7. Types of surgery with nausea and vomiting during 24 hours postoperatively $(\mathrm{N}=2,398)$

\begin{tabular}{|l|c|c|c|c|}
\hline \multirow{2}{*}{ Types of surgery } & \multicolumn{2}{|c|}{ Nausea } & \multicolumn{2}{c|}{ Vomiting } \\
\cline { 2 - 5 } & $\begin{array}{c}\text { No } \\
\mathbf{n}(\%)\end{array}$ & $\begin{array}{c}\text { Yes } \\
\mathbf{n}(\%)\end{array}$ & $\begin{array}{c}\text { No } \\
\mathbf{n}(\%)\end{array}$ & $\begin{array}{c}\text { Yes } \\
\mathbf{n}(\%)\end{array}$ \\
\hline Obstetrics and Gynecology & $372(65.3)$ & $198(34.7)^{*}$ & $492(86.3)$ & $78(13.7)$ \\
\hline General & $358(70.8)$ & $148(29.2)$ & $452(89.3)$ & $54(10.7)$ \\
\hline Ear, nose, throat & $137(62.3)$ & $83(37.7)$ & $191(86.8)$ & $29(13.2)$ \\
\hline Orthopedics & $189(75.0)$ & $63(25.0)^{*}$ & $229(90.9)$ & $23(9.1)$ \\
\hline Urology & $234(81.5)$ & $53(18.5)^{*}$ & $272(94.8)$ & $15(5.2)^{*}$ \\
\hline Laparoscopic & $166(54.8)$ & $137(45.2)^{*}$ & $254(83.8)$ & $49(16.2)^{*}$ \\
\hline ophthalmology & $45(91.8)$ & $4(8.2)$ & $49(100)$ & $0(0)$ \\
\hline Neurosurgery & $51(72.9)$ & $19(27.1)$ & $65(92.9)$ & $5(7.1)$ \\
\hline plastic & $42(60.9)$ & $27(39.1)$ & $60(87.0)$ & $9(13.0)$ \\
\hline vascular & $23(85.2)$ & $4(14.8)$ & $26(96.3)$ & $1(3.7)$ \\
\hline Thoracic & $3(100)$ & $0(0)$ & $3(100)$ & $0(0)$ \\
\hline Pediatric & $10(71.4)$ & $4(28.6)$ & $11(78.6)$ & $3(21.4)$ \\
\hline maxillofacial & $21(75.0)$ & $7(25.0)$ & $26(92.9)$ & $2(7.1)$ \\
\hline
\end{tabular}

$" p<.05$

\section{Discussion}

The present study showed an overall nausea rate of $31.2 \%$, and a total incidence of vomiting of $11.2 \%$. These rates are comparable with the results that were reported in the meta-analysis and other studies $[1,7,9]$.

Apfel et al. [10] determined that female gender, nonsmoking status, history of PONV or motion sickness and the use of postoperative opioids were strong predictors of PONV. Our findings indicated that female gender, the use of postoperative opioids and duration of anesthesia more than 60 minute are predictors of PONV; while nonsmoking status, previous history of PONV or motion sickness, age of patients, type of anesthesia are not predictors of PONV. Female gender appears to be the most important predictor of PONV as shown in many studies $[11,12]$. These results emphasize the importance of giving more attention patients postoperatively if the gender is female, and or, the duration of anesthesia is more than 60 minutes, and or patients received postoperative opioids. Furthermore, nonsmoking status in our study was not a significant predictor for PONV, either in recovery room or 24 hours postoperatively, which contradicts Apfel study. We can claim that our sample was large, and patients underwent different types of surgery, thus, smoking history is not a significant factor to be considered for further precautions for both nausea and vomiting postoperatively.

Sample size related to history of PONV in our study was relatively small, however, it was found to be of no predictive value on the occurrence of PONV. This finding is consistent with another study by Stadler et al. [13]. In our survey, nonsmoking status has no predictive value on the occurrence of PONV, which contradict the results of many studies $[6,14,15]$. Furthermore, these studies showed that smoking decreases the rate of PONV. The exact cause of smoking as a factor reducing the rate of PONV is unknown. Apfel et al. [10] found that nonsmoking status was not a predictive risk of nausea and vomiting after discharge of ambulatory surgery patients (PDNV). This finding could be justified by what Apfel reported that the decreased rate of PONV in smokers was due to immediate withdrawal of nicotine before surgery and not the nicotine itself since application of nicotine patches before surgery increase rate of PONV.

The use of postoperative opioids in our study increased the incidence of PONV. In addition, the use of opioids was found as a predictor for nausea but not vomiting, and this is in accordance with the results of other studies [5,13]. Apfel et al. [16] in a prospectively collected data from two centers to find predictive score system for PONV found that the use of post-operative opioids was the fourth predictive risk factor for the development of PONV. In our sample, we used $1 \mathrm{mg} / \mathrm{kg}$ of pethidine or about $75-100 \mathrm{mg}$ in adults and/or $0.1 \mathrm{mg} / \mathrm{kg}$ of morphine to treat post-operative pain, and this dose possibly played a major factor for the increase of PONV related to post-operative opioids.

In our study, the type of anesthesia whether local or general were not significant predictors for the occurrence of PONV. For our patients, we did not use nitrous oxide; and propofol was the main anesthetic induction agent that possibly reduced the incidence of PONV related to general anesthesia [15]. Our results related to the effect of anesthesia on rate of PONV contradict the results by Stadler et al. [13] who reported higher incidence of PONV in general anesthesia than local anesthesia. Borgeatet el al. [15] in their review about PONV associated with regional block indicated that the rate of nausea was $21 \%$ and vomiting was $11 \%$ and these rates were almost similar to our results for PONV, which associated with general anesthesia. Our result was similar to Borgeatet et al. [15] regarding the choice of local anesthesia as it did not affect the rate of PONV; the addition of fentanyl to spinal block did not increase the rate of PONV; and during general anesthesia, the use of propofol and omitting nitrous oxide did narrow the gap between general anesthesia and spinal block in production of PONV. Furthermore, in our study, spinal block for obstetric, orthopedics and urology patients were used in about $90 \%$ of patients who had regional block.

Although the age of less than 40 years was found with higher rate of nausea in the PACU, age of the patients in this study was not found to be a significant predictor for PONV. Apfel et al. [17] in their research about the cause of PONV found that young age was the main predictor for vomiting between 2-24 hours postoperatively. In another study, it was found that age of less than 50 years is predictive risk factor for PONV in day case surgery [11]. Type of surgery is widely assumed as a risk factor for PONV $[4,18]$. In our study, gynecologic and obstetric, orthopedic, urologic and laparoscopic surgery increases the rate of nausea while only laparoscopic and urologic surgery increases both nausea and vomiting. Although many authors $[19,20]$ have pointed out the relationship between type of surgery and PONV, still no sufficient evidence to find a causal relationship between the type of surgery and PONV $[7,4]$.

Apfel et al. [16] in their study to find a risk score to predict PONV, found that type of operation was not a strong independent risk factor for PONV. Some authors believe that type of anesthetic agents or female patients as in laparoscopy surgery were the main factors for the development of PONV rather than the surgery itself. In our patients sample $96 \%$ of vomiting episodes was preceded by nausea and there were no complications related to vomiting. Many researchers argued 
that the difference in the rate and risk factors for PONV could be explained by the physiology of the two events and they recommended that the study of nausea and vomiting should be done on separate endpoints [12,21,22].

In conclusion, this survey supports the clinical impression that PONV incidence is still high despite improvement in anesthetic and surgical care. The female gender, use of postoperative opioids and duration of anesthesia were the main significant risk factors for PONV.

\section{References}

1. Apfel CC, Heidrich FM, Jukar-Rao S, Jalota L, Hornuss C, et al. (2012) Evidencebased analysis of risk factors for postoperative nausea and vomiting. Br J Anaesth 109: 742-753. [Crossref]

2. McCracken G, Houston P, Lefebvre G; Society of Obstetricians and Gynecologists of Canada (2008) Guideline for the management of postoperative nausea and vomiting. $J$ Obstet Gynaecol Can 30: 600-607, 608-16. [Crossref]

3. Kovac AL (2000) Prevention and treatment of postoperative nausea and vomiting. Drugs 59: 213-243. [Crossref]

4. Garg S, Subramani S, Sachdeva H (2017) Postoperative nausea and vomiting: The achilles heel of anesthesiologists. J Anaesthesiol Clin Pharmacol 33: 427-428. [Crossref]

5. Kranke P, Eberhart L (2011) Possibilities and limitations in the pharmacological management of postoperative nausea and vomiting. Eur J Anaesthesiol 28: 758-765. [Crossref]

6. Marret E, Kurdi O, Zufferey P, Bonnet F (2005) Effects of nonsteroidal antiinflammatory drugs on patient-controlled analgesia morphine side effects: Metaanalysis of randomized controlled trials. Anesthesiology 102: 1249-1260. [Crossref]

7. AlJabari A, Massad I, Alzaben K (2016) Post-operative nausea, vomiting and pain score in post anesthesia care unit (PACU) at Jordan university hospital. J Anesth Clin Res 7.

8. IBM Corporation (2012) IBM SPSS Statistics for Windows, Version 21.0 NY: IBM Corp.

9. Gan TJ, Diemunsch P, Habib AS, Kovac A, Kranke P (2014) Consensus guidelines for the management of postoperative nausea and vomiting. Anesth Analg 118: 85-113. [Crossref]
10. Apfel C, Phillip B, Camakkaya O (2012) Who is at risk for post-discharge nausea and vomiting after ambulatory surgery? Anesthesiology 117: 475-486. [Crossref]

11. Dewinter G, Staelens W, Veef E, Teunkens A, Van de Velde M, et al. (2018) Simplified algorithm for the prevention of postoperative nausea and vomiting: a before-and-after study. Br J Anaesth 120: 156-163. [Crossref]

12. Efune PN, Minhajuddin A, Szmuk P (2018) Incidence and factors contributing to postdischarge nausea and vomiting in pediatric ambulatory surgical cases. Paediatr Anaesth 28: 257-263. [Crossref]

13. Stadler M, Bardiau F, Seidel L, Albert A, Boogaerts JG (2003) Difference in risk factors for postoperative nausea and vomiting. Anesthesiology 98: 46-52. [Crossref]

14. Apfel C, Greim C, Haubitz I, Grundt D, Geopfert C, et al. (1998) The discriminating power of a risk score for postoperative vomiting in adults undergoing various types of surgery. Acta Anesthesiol Scand 42: 502-509. [Crossref]

15. Borgeat A, Ekatodramis G, Schenker C (2003) Postoperative nausea and vomiting in regional anesthesia: A review. Anesthesiology 98: 530-547. [Crossref]

16. Apfel C, Laara E, Koivuranta M, Greim C, Roewer N (1999) A simplified risk score for predicting postoperative nausea and vomiting. Anesthesiology 91: 693-700. [Crossref]

17. Apfel CC, Kranke P, Eberhart LH, Roos A, Roewer N (2002) Comparison of predictive models for postoperative nausea and vomiting. Br J Anaesth 88: 234-240. [Crossref]

18. Kappen T (2018) Risk-tailored prophylaxis for postoperative nausea and vomiting: has the big little problem gotten any smaller? Br J Anaesth 120: 9-13. [Crossref]

19. Hu X, Gan T, Habib A, Chen Y, Taguchi A (2006) Postoperative nausea and vomiting following inpatient surgeries in a teaching hospital: a retrospective database analysis. Curr Med Res Opin 22: 1093-1099. [Crossref]

20. Gan T, Meyar T, Apfel C (2007) Society for ambulatory anesthesia guidelines for the managment of postoperative nausea and vomiting. Anesth Analg 105: 1615-1628 [Crossref]

21. Webb A, Leong S, Myles P, Burn S (2002) The addition of a tramadol infusion to morphine patient-controlled analgesia after abdominal surgery: a double-blinded, placeb-controlled randomized trial. Anesth Analg 95: 1713-1718. [Crossref]

22. Gan TJ (2006) Risk factors for postoperative nausea and vomiting. Anesth Analg 102 1884-1898. [Crossref]

Copyright: (C2019 Al-Ghanem SS. This is an open-access article distributed under the terms of the Creative Commons Attribution License, which permits unrestricted use, distribution, and reproduction in any medium, provided the original author and source are credited. 